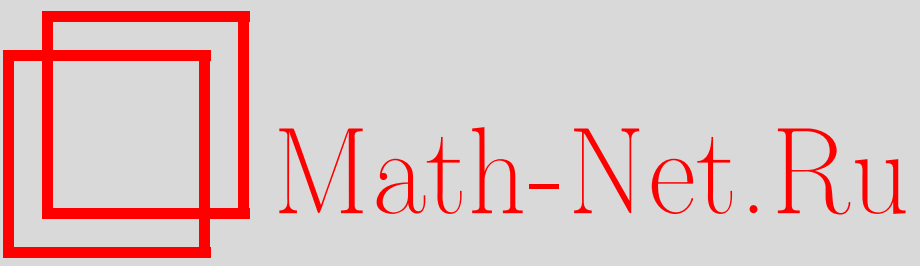

A. G. Losev, V. V. Filatov, Liouville type theorems for solutions of semilinear equations on non-compact Riemannian manifolds, Vestn. Udmurtsk. Univ. Mat. Mekh. Komp. Nauki, 2021, Volume 31, Issue 4, 629-639

DOI: https://doi.org/10.35634/vm210407

Use of the all-Russian mathematical portal Math-Net.Ru implies that you have read and agreed to these terms of use

http://www.mathnet.ru/eng/agreement

Download details:

IP: 3.91 .87 .62

April 26, 2023, 16:22:37 
MSC2020: 58J05

\author{
(C) A. G. Losev, V. V. Filatov
}

\title{
LIOUVILLE TYPE THEOREMS FOR SOLUTIONS OF SEMILINEAR EQUATIONS ON NON-COMPACT RIEMANNIAN MANIFOLDS
}

It is proved that the Liouville function associated with the semilinear equation $\Delta u-g(x, u)=0$ is identical to zero if and only if there is only a trivial bounded solution of the semilinear equation on non-compact Riemannian manifolds. This result generalizes the corresponding result of S. A. Korolkov for the case of the stationary Schrödinger equation $\Delta u-q(x) u=0$. The concept of the capacity of a compact set associated with the stationary Schrödinger equation is also introduced and it is proved that if the capacity of any compact set is equal to zero, then the Liouville function is identically zero.

Keywords: Liouville type theorem, semilinear elliptic equations, Riemannian manifolds, massive sets, Liouville function.

DOI: $10.35634 / \mathrm{vm} 210407$

\section{Introduction}

Let $M$ be a smooth connected non-compact Riemannian manifold, $\Delta$ be the Laplace-Beltrami operator on $M$. We consider the following semilinear elliptic equation on $M$ :

$$
L u=\Delta u-g(x, u)=0,
$$

where $g(x, u)$ is a Lipschitz function, not identical to zero on $M \times \mathbb{R}$ with several structural conditions, which will be stated later.

The origins of the topic relate to the classification theory of two dimensional Riemannian non-compact surfaces and manifolds. A distinctive property of parabolic type surfaces is the fulfillment of the Liouville type theorem, which claims that any positive superharmonic function on these surfaces is constant. This property of surfaces was later taken as a definition of parabolic type manifolds.

Numerous articles are dedicated to obtaining conditions under which a manifold has parabolic type in terms of volume of geodesic balls, area section, sectional curvature, Ricci curvature, capacity and etc. One of the first geometric results in this direction is the famous theorem of S.Y. Cheng and S.T. Yau [2] which states that a complete Riemannian manifold has the parabolic type if volume of the geodesic ball with the radius $R$ grows not faster than $R^{2}$ as $R \rightarrow \infty$.

The capacitive technique showed high efficiency in the classification theory of non-compact Riemannian manifolds (see, for example, [3,9,11]). In particular, in the work [4] A.A. Grigor'yan proved that parabolicity is equivalent to the fact that the variational capacity of any (some) compact set is equal to zero. A general overview of this matter can be found in $[3,16]$.

The problems of the existence of nontrivial harmonic and subharmonic functions naturally lead to theorems of the Liouville type, which are the most popular part of the topic under consideration. Dozens of mathematical papers are devoted to these questions. However, quite a few exact results have been obtained; as a rule, necessary or sufficient conditions for the triviality of various classes of solutions of differential equations are published.

The classic Liouville theorem claims that any bounded harmonic function in $\mathbb{R}^{n}$ is identically constant. A more general approach to the theorems of Liouville type has been developed recently. 
Namely, let $L$ be an elliptic operator on $M, A$ be some functional class. We say that $M$ possesses $(A, L)$-Liouville property if any solution (subsolution) of the equation

$$
L u=0
$$

from class $A$ is constant. In the case if $L$ is a linear operator, then there is a point in raising question about dimension of the solution space of this equation.

Many works are devoted to these questions. They consider different sets $A$ (bounded, positive, summable, having a finite energy integral, etc.) of solutions of linear and quasilinear elliptic equations and inequalities $[8,17,19]$.

A vast number of works are devoted to the study of solutions of elliptic equations on Riemannian manifolds with a finite number of ends, see [11,12]. Let $M$ be a complete non-compact Riemannian manifold. We say that an open set $E \subset M$ is an end if it is connected, not bounded, and its boundary $\partial E$ is a compact set. We say that $M$ is a manifold with ends if $M$ can be represented as a union of a compact set and a finite number of disjoint ends.

In the overwhelming majority of articles, the ends of the parabolic and hyperbolic types are distinguished. Note that the end $E$ has the hyperbolic type if and only if there is a nontrivial harmonic function $v$ on $E$ such that $0 \leq v<1$ and $\left.v\right|_{\partial E}=0$. Such a function $v$ is usually called the equilibrium potential of $E$.

However, the limitation on the structure of manifolds with ends is rather strict. Developing the capacitive approach, A. Grigor'yan in [3] introduced the concept of massive ( $D$-massive) set. Using this concept A. Grigor'yan obtained an exact estimate of dimension of spaces of bounded harmonic functions (with a finite Dirichlet integral) on arbitrary non-compact Riemannian manifolds.

Later, A. Grigor'yan and A. Losev [6] obtained an estimate of the dimension of spaces of bounded solutions of the stationary Schrödinger equation

$$
\Delta u-q(x) u=0
$$

using the concept of $q$-massive sets, here $q(x) \geq 0$ is a smooth function. Namely results of [6,13] can be joined in the following theorem.

Theorem 1 (see [6,13]). The dimension of the space of bounded solutions of the stationary Schródinger equation (with a finite Dirichlet integral) is not less than $m \geq 1$ if and only if $M$ contains $m$ pairwise disjoint q-massive ( $q D$-massive) subsets.

In recent years, a fairly large number of researches have appeared on Liouville type theorems, as well as the solvability of various boundary value problems for semilinear equations and inequalities on non-compact Riemannian manifolds [1,7,14, 18].

For example, E.A. Mazepa [15] proved that a manifold has only trivial bounded solutions of equation (0.1) if and only if the manifold has only trivial bounded solutions of equation (0.2) with $q(x)=1$. We should note that the last theorem is valid only under the condition that there is a constant $A>0$ such a as $A g(x, \xi) \geq \xi$ for all $\xi \geq 0$, we do not imply such condition in this article.

The main aim of this paper is to obtain Liouville type theorems for solutions of equations $(0.1)$ and (0.2).

\section{$\S 1$. Massive sets}

Let $M$ be a non-compact Riemannian manifold. Let $g(x, \xi)$ from $(0.1)$ be a Lipschitz function on $M \times \mathbb{R}$, not identically zero, which satisfies the following conditions:

- $g(x,-\xi)=-g(x, \xi)$; 
- $g\left(x, \xi_{1}\right) \geq g\left(x, \xi_{2}\right), \quad \forall \xi_{1}, \xi_{2}: \xi_{1}>\xi_{2}$.

We need the following definition.

Definition 1. Let $\Omega \subset M$ be an open set, i.e., $\Omega \neq M$. We will call a continuous function $u$ on $\Omega$ a subsolution of the semilinear equation (0.1) if for any precompact set $G \subset \Omega$ and any solution $v$ of (0.1) in $G$ such as $v_{\partial G}=u_{\partial G}$ inequality $u \leq v$ holds in $G$.

We will need the following properties of the solutions and subsolutions of semilinear equation $(0.1)$.

Lemma 1 (Comparison principle, see [15]). Let $\Omega \subset M$ be a precompact set. If functions $u, v \in C^{2}(\Omega) \cap C(\bar{\Omega})$ satisfy the inequalities

$$
\Delta u \geq g(x, u), \quad \Delta v \leq g(x, v),\left.\quad u\right|_{\partial \Omega} \leq v_{\partial \Omega},
$$

then $u \leq v$ in $\Omega$.

Corollary 1. Let $\Omega \subset M$ be a precompact set. If a function $u \in C^{2}(\Omega) \cap C(\bar{\Omega})$ satisfies the inequality

$$
\Delta u-g(x, u) \geq 0
$$

in $\Omega$, then $u$ is a subsolution of the semilinear equation (0.1).

Lemma 2 (Maximum principle, see [15]). Let $\Omega \subset M$ be a precompact set. If function $u \in$ $\in C^{2}(\Omega) \cap C(\bar{\Omega})$ satisfies the inequality $\Delta u-g(x, u) \geq 0(\Delta u-g(x, u) \leq 0)$ in $\Omega$ then

$$
\sup _{\Omega} u \leq \sup _{\Omega} u^{+} \quad\left(\inf _{\Omega} u \geq \inf _{\partial \Omega} u^{-}\right) .
$$

In case if $u$ is a solution of (0.1), then

$$
\sup _{\Omega}|u|=\sup _{\partial \Omega}|u|
$$

Lemma 3 (see [15, Lemma 1]). Let $G \subset M$ be an arbitrary precompact open set and $\left\{\phi_{k}\right\}_{k=1}^{\infty}$ be a uniformly bounded family of solutions of equation (0.1), $\phi_{k} \in C^{2, \alpha}(G)$. Then the functional family $\left\{\phi_{k}\right\}_{k=1}^{\infty}$ is a compact set as well as families of its first and second derivatives on any compact subset $G^{\prime} \subset G$.

Now we state the definition of $L$-massive sets.

Definition 2. Let $\Omega \subset M$ and $L$ be an open proper set. We will call $\Omega L$-massive if there is a subsolution of $(0.1)$ on $M$ such that $u=0$ on $M \backslash \Omega$ and $0 \leq u \leq 1$. We will refer to such a function as inner potential of $\Omega$.

It is obliviously from the maximum principle that any $L$-massive set is non-compact. Also, $L$-massive sets have the following property.

Lemma 4 (see [13]). Let $\Omega_{1} \subset \Omega_{2}$ are proper open subsets of $M$. If $\Omega_{1}$ is L-massive then $\Omega_{2}$ is also L-massive. In the case if $\overline{\Omega_{2}} \backslash \Omega_{1}$ is a compact set and $\Omega_{2}$ is L-massive, then $\Omega_{1}$ is also L-massive.

Lemma 5 (see [13]). On the manifold $M$, there exists a nontrivial bounded solution of $(0.1)$ if and only if there is an L-massive set on $M$.

The proofs can be found, for example, in [13]. 


\section{§ 2. Liouville type theorem for solutions of semilinear equation on non-compact Riemannian manifolds}

Let $\Omega$ be an open subset of $M,\left\{B_{k}\right\}_{k=1}^{\infty}$ be a smooth exhaustion of $M$, i.e., a sequence of precompact open subsets of $M$ such that $\overline{B_{k}} \subset B_{k+1}, M=\bigcup_{k=1}^{\infty} B_{k}$ and $u_{k}$ be a solution to the following Dirichlet problem in $\Omega \cap B_{k}$ :

$$
\left\{\begin{array}{l}
\Delta u_{k}-g\left(x, u_{k}\right)=0, \quad x \in \Omega \cap B_{k} ; \\
u=0, \quad x \in \partial \Omega \cap B_{k} ; \\
u=1, \quad x \in \Omega \cap \partial B_{k} .
\end{array} .\right.
$$

The sequence of functions $\left\{u_{k}\right\}_{k=1}^{\infty}$ decreases and is bounded by the maximum principle (Lemma 2). Let us show that it indeed decreases. Considering $u_{k}$ and $u_{k+1}$ on $B_{k}$, we get that $\left.u_{k}\right|_{\partial \Omega \cap B_{k}}=\left.u_{k+1}\right|_{\partial \Omega \cap B_{k}}=0$ and $\left.u_{k}\right|_{\Omega \cap \partial B_{k}}=1 \geq\left. u_{k+1}\right|_{\Omega \cap \partial B_{k}}$; thus, by the comparison principle (Lemma 1), we get that $u_{k} \geq u_{k+1}$ in $B_{k}$.

Definition 3. The limit function $u_{\Omega}=\lim _{k \rightarrow \infty} u_{k}$ will called a $L$-harmonic measure of the set $\Omega$. In the case $\Omega=M$, the function $L_{M} \equiv u_{M}$ is called the a Liouville function associated with equation $(0.1)$ of the manifold $M$.

We should notice that, from Lemma 3, we get that $\Delta u_{\Omega}-g\left(x, u_{\Omega}\right)=0$. Obviously, by virtue of the maximum principle in the case of precompact $\Omega$, we have $u_{\Omega} \equiv 0$. The Liouville function associated with the stationary Schródinger equation (0.2) was used in [5] and [6].

Theorem 2. The Liouville function associated with (0.1) of the manifold $M$ is identical zero if, and only if for any $\Omega \subset M$, the harmonic measure $u_{\Omega} \equiv 0$.

P r o o f. Let $L_{M} \equiv 0$ and $u_{k}$ be a solution to the following Dirichlet problem in $B_{k}$ :

$$
\left\{\begin{array}{l}
\Delta u_{k}-g\left(x, u_{k}\right)=0, \quad x \in B_{k} \\
\left.u_{k}\right|_{\partial B_{k}}=1 .
\end{array}\right.
$$

We have that $L_{M}=\lim _{k \rightarrow \infty} u_{k} \equiv 0$ by our assumption.

Now let $u_{k}^{\prime}$ be a solution to the following Dirichlet problem in $\Omega \cap B_{k}$ :

$$
\left\{\begin{array}{l}
\Delta u_{k}^{\prime}-g\left(x, u_{k}^{\prime}\right)=0, \quad x \in \Omega \cap B_{k} ; \\
u_{k}^{\prime}=0, \quad x \in \partial \Omega \cap B_{k} ; \\
u_{k}^{\prime}=1, \quad x \in \Omega \cap \partial B_{k} .
\end{array}\right.
$$

Taking into account the maximum principle, we get that $0 \leq u_{k} \leq 1, x \in B_{k} \cap \Omega$. It follows that $0 \leq u_{k}^{\prime} \leq u_{k}$ in $\left(\partial \Omega \cap B_{k}\right) \cup\left(\partial B_{k} \cap \Omega\right)$. It follows from the maximum principle that $0 \leq u_{k}^{\prime} \leq u_{k}$ in $\Omega \cap B_{k}$. Passing to the limit as $k \rightarrow \infty$, we obtain that $0 \leq u_{\Omega} \leq L_{M} \equiv 0$ in $\Omega$, whence the required result follows.

Now we prove the other part of the theorem, by supposing the opposite. We get that every harmonic measure is $u_{\Omega} \equiv 0$, but the Liouville function is not trivial. According to Lemma 5, we got that there is a massive set $\Omega$, let $v$ be its inner potential. Constructing harmonic measure of $\Omega$

$$
\left\{\begin{array}{l}
\Delta u_{k}-g\left(x, u_{k}\right)=0, \quad x \in \Omega \cap B_{k} ; \\
u=0, \quad x \in \partial \Omega \cap B_{k} \\
u=1, \quad x \in \Omega \cap \partial B_{k} .
\end{array}\right.
$$

we got that $u_{k} \geq v$ in $\Omega \cap B_{k}$ (according to the comparison principle). Passing to limit $k \rightarrow \infty$, we get that $u_{\Omega} \geq v$ and $v$ is nontrivial, but then $u_{\Omega}$ is also non-trivial. We got contradiction, which proves the theorem. Q.E.D. 
Theorem 3. If the Liouville function associated with (0.1) of the manifold $M$ is identically zero, then every bounded solution of the semilinear equation (0.1) is identically zero.

P r o o f. Suppose the opposite, i.e., that, on $M$, there exists a nontrivial, bounded solution to the equation $\Delta u-g(x, u)=0$. Then, according to Lemma 5, there is a $L$-massive subset of $M$; we denote it by $\Omega$, and $v$ is the inner potential of $\Omega$. Without loss of generality, we can assume that $0 \leq v \leq 1$.

Let $u_{k}$ be a solution to the following Dirichlet problem in $\Omega \cap B_{k}$ :

$$
\left\{\begin{array}{l}
\Delta u_{k}-g\left(x, u_{k}\right)=0, \quad x \in \Omega \cap B_{k} \\
u_{k}=0=v, \quad x \in \partial \Omega \cap B_{k} \\
u_{k}=v, \quad x \in \Omega \cap \partial B_{k}
\end{array}\right.
$$

Taking into account that $v$ is a nontrivial subsolution of the semilinear equation, we obtain $v \leq u_{k} \leq 1$ in $\Omega \cap B_{k}$.

Now let $u_{k}^{\prime}$ be a solution to the following Dirichlet problem in $\Omega \cap B_{k}$ :

$$
\left\{\begin{array}{l}
\Delta u_{k}^{\prime}-g\left(x, u_{k}^{\prime}\right)=0, \quad x \in \Omega \cap B_{k} \\
u_{k}^{\prime}=0, \quad x \in \partial \Omega \cap B_{k} \\
u_{k}^{\prime}=1, \quad x \in \Omega \cap \partial B_{k}
\end{array}\right.
$$

Using the comparison principle, we get that $0 \leq u_{k} \leq u_{k}^{\prime}$ in $\Omega \cap B_{k}$. Since $L_{M} \equiv 0$, then according the Theorem 1 , we conclude that $\lim _{k \rightarrow \infty} u_{k}^{\prime}=u_{\Omega} \equiv 0$, as a consequence $\lim _{k \rightarrow \infty} u_{k} \equiv 0$. However, $u_{k} \geq v$, where $v$ is a nontrivial subsolution of the semilinear equation. We got a contradiction, which proves the theorem. Q.E.D.

Remark 1. We should note that, obviously, if any bounded solution of (0.1) is zero, then $L_{M} \equiv 0$.

Remark 2. These theorems generalize the corresponding results of S. A. Korolkov [10] for the case of solutions of (0.2).

\section{§3. Capacity characteristics and the Liouville type theorems for solutions of stationary Schrödinger equation}

In this part of the article we will consider only solutions of the stationary Schrodinger equation (0.2). We will remind potential theory of harmonic functions on manifolds (see [3]).

Let $\Omega \subset M$ be an open set and $B$ be a compact set in $\Omega$. We will call the pair $(B, \Omega)$ the capacitor and define its capacity by

$$
\operatorname{cap}(B, \Omega)=\inf _{\phi \in L(B, \Omega)} \int_{\Omega \backslash B}|\nabla \phi|^{2} d x
$$

where $L(B, \Omega)$ is a set of locally Lipschitz functions $\phi$ on $M$ with a compact support in $\bar{\Omega}$, such that $0 \leq \phi \leq 1$ and $\left.\phi\right|_{B}=1$. Let $\left\{B_{k}\right\}_{k=1}^{\infty}$ be a smooth exhaustion of $M$. The capacity of compact $B$ will be defined

$$
\operatorname{cap}(B):=\lim _{k \rightarrow \infty} \operatorname{cap}\left(\bar{B}, B_{k}\right) .
$$

It is easy to prove using the Dirichlet principle (see [13]) that the infimum in definition of capacity is reached at function $\phi=u$, which is the solution to the following Dirichlet problem in $\Omega \backslash B$ :

$$
\left\{\begin{array}{l}
\Delta u=0 \\
\left.u\right|_{\partial B}=1 \\
\left.u\right|_{\partial \Omega}=0
\end{array}\right.
$$


and, as a consequence,

$$
\operatorname{cap}(B, \Omega)=\int_{\Omega \backslash B}|\nabla u|^{2} d x .
$$

Such a function $u$ is called an equilibrium potential of capacitor $(B, \Omega)$.

A. Grigor'yan [3] proved that the capacity of some (any) compact set is equal to zero if and only if the manifold has the parabolic type. If we use similar approach and define the capacity associated with equation $(0.2)$ by

$$
\operatorname{cap}(B, \Omega)=\inf _{\phi \in L(B, \Omega)} \int_{\Omega \backslash B}|\nabla \phi|^{2}+q(x) \phi^{2} d x
$$

then such a capacity will have properties corresponding to the properties of the capacity associated with harmonic functions, but it is impossible to obtain the Liouville type theorem for solutions of $(0.1)$ due to the fact that such a capacity will always be positive. Moreover S.A. Korolkov and A.G. Losev [11] proved that the dimension of the space of bounded solutions of $(0.2)$ on manifolds with ends is not less than $l$, where $l$ is the number of ends of the hyperbolic type.

We obtain such Liouville theorem but with the different approach to the capacity. Let $B$ be a compact set and $\left\{B_{k}\right\}_{k=1}^{\infty}$ be a smooth exhaustion of $M$. Without loss of generality, we can assume that $B \subset B_{k}$. Let us consider solutions of the following Dirichlet problems in $B_{k}$ :

$$
\left\{\begin{array}{l}
\Delta h_{k}-q(x) h_{k}=0, \\
\left.h_{k}\right|_{\partial B}=1 \\
\left.h_{k}\right|_{\partial B_{k}}=1
\end{array}\right.
$$

Sequence $h_{k}$ is monotonically decreasing and, as consequence, there is $h_{B}=\lim _{k \rightarrow \infty} h_{k}$; we will refer to $h_{B}$ as the Liouville function of exterior of the compact set $B$.

Using the idea, which was introduced in [6], we will consider the following operator:

$$
\Delta_{h_{B}} f=\frac{1}{h_{B}^{2}} \operatorname{div}\left(h_{B}^{2} \nabla f\right) .
$$

It is simple to obtain that

$$
\Delta_{h_{B}} f=\Delta f+\frac{2}{h_{B}} \nabla f \nabla h_{B}
$$

Definition 4. We will define the capacity of the capacitor $(B, \Omega)$ by

$$
\operatorname{cap}(B, \Omega)=\inf _{\phi \in L(B, \Omega)} \int_{\Omega \backslash B} h_{B}^{2}|\nabla \phi|^{2} d x .
$$

Due to the Dirichlet principle (see [13]), the infimum in the definition of the capacity is reached at the function $\phi=z$ which is the solution to the following Dirichlet problem in $\Omega \backslash B$ :

$$
\left\{\begin{array}{l}
\Delta_{h_{B}} z=0 \\
\left.z\right|_{\partial B}=1 \\
\left.z\right|_{\partial \Omega}=0
\end{array}\right.
$$

It is obvious that $\operatorname{cap}(B, \Omega)$ is decreasing with enlargment of $\Omega$ (and decrease of $B$ ); then we can define the capacity of $B$ by

$$
\operatorname{cap}(B)=\lim _{k \rightarrow \infty} \operatorname{cap}\left(B, B_{k}\right)
$$


Let $s_{k}$ be solutions for the following Dirichlet problems:

$$
\left\{\begin{array}{l}
\Delta s_{k}-q(x) s_{k}=0, \\
\left.s_{k}\right|_{\partial B}=1 \\
\left.s_{k}\right|_{\partial B_{k}}=0
\end{array}\right.
$$

The sequence $s_{k}$ is monotonically increasing and bounded, we will denote $s_{B}=\lim _{k \rightarrow \infty} s_{k}$. From this point onward, we will use the notation $h=h_{B}, s=s_{B}$.

Lemma 6. If $\operatorname{cap}(K)=0$, then $s=h$.

P r o o f. Let us denote $f=\frac{s}{h}$. Now we obtain some equality:

$$
\begin{gathered}
0=\Delta s-q(x) s=\Delta\left(\frac{s h}{h}\right)-q(x) \frac{s h}{h}=\Delta f h-q(x)(f h)= \\
=h \Delta f+2 \nabla f \nabla h+f(\Delta h-q(x) h)=h \Delta_{h} f .
\end{gathered}
$$

Hence, we get that $h \Delta_{h_{k}} f=0$ and $f_{k}$ is a solution of the equation $\Delta_{h} f_{k}=0$. Moreover, $f_{k}$ is the equilibrium potentials of $\left(B, B_{k}\right)$, due to the fact that $\Delta_{h_{K}} f_{k}=0$ and $\left.f\right|_{\partial B}=1,\left.f\right|_{\partial B_{k}}=0$. And if $\operatorname{cap}(K)=0$, then $f=1$, which is equal to $s=h$. Q.E.D.

Theorem 4. The Liouville function associated with (0.2) $L_{M} \equiv 0$ if and only for any compact set $K$ its capacity $\operatorname{cap}(K)=0$.

P r o o f. Let $L_{M} \equiv 0$. We will consider $t_{k}=h_{k}-s_{k}$. It is obvious that $t_{k}$ is the solution of (0.2) in $B_{k} \backslash B$ and $\left.t_{k}\right|_{\partial B}=0,\left.t_{k}\right|_{\partial B_{k}}=1$. Thus, we get by definition that $t=\lim _{k \rightarrow \infty} t_{k}$ is the harmonic measure of $M \backslash B$. Since $L_{M} \equiv 0$, then, according to Theorem 2, we also get that $t \equiv 0$.

Let $\operatorname{cap}(B)=0$ for any compact set $B$. Supposing the opposite we get that there is a nontrivial $L_{M}$, which according, to Theorem 2, is equal to the existence of $\Omega \subset M$ with nontrivial harmonic measure $u_{\Omega}$. As it was shown earlier, we get that $u_{\Omega}=h_{\Omega}-s_{\Omega}$, and since $u_{\Omega} \neq 0$, then $s_{\Omega} \neq h_{\Omega}$, which equals to $\operatorname{cap}(\Omega)>0$. We got contradiction, which proofs the theorem. Q.E.D.

Funding. The reported study was funded by RFBR, project no. 20-31-90110.

\section{REFERENCES}

1. Caristi G., Mitidieri E., Pohozaev S. I. Some Liouville theorems for quasilinear elliptic inequalities, Doklady Mathematics, 2009, vol. 79, no. 1, pp. 118-124.

https://doi.org/10.1134/S1064562409010360

2. Cheng S. Y., Yau S. T. Differential equations on Riemannian manifolds and their geometric applications, Communications on Pure and Applied Mathematics, 1975, vol. 28, no. 3, pp. 333-354. https://doi.org/10.1002/cpa.3160280303

3. Grigor'yan A. Analytic and geometric background of recurrence and non-explosion of the Brownian motion on Riemannian manifolds, Bulletin of the American Mathematical Society, 1999, vol. 36, no. 2, pp. 135-249. https://doi.org/10.1090/S0273-0979-99-00776-4

4. Grigor'yan A. A. On the existence of positive fundamental solutions of the Laplace equation on Riemannian manifolds, Mathematics of the USSR-Sbornik, 1987, vol. 56, no. 2, pp. 349-358. https://doi.org/10.1070/SM1987v056n02ABEH003040

5. Grigor'yan A., Hansen W. A Liouville property for Schrödinger operators, Mathematische Annalen, 1998, vol. 312, no. 4, pp. 659-716. https://doi.org/10.1007/s002080050241 
6. Grigor'yan A. A., Losev A. G. Dimension of spaces of solutions of the Schrödinger equation on noncompact Riemannian manifolds, Mathematical Physics and Computer Simulation, 2017, vol. 20, no. 3, pp. 34-42 (in Russian). https://doi.org/10.15688/mpcm.jvolsu.2017.3.3

7. Grigor'yan A., Sun Y. On positive solutions of semi-linear elliptic inequalities on Riemannian manifolds, Calculus of Variations and Partial Differential Equations, 2019, vol. 58, no. 6, 207. https://doi.org/10.1007/s00526-019-1645-6

8. Grigor'yan A., Verbitsky I. Pointwise estimates of solutions to semilinear elliptic equations and inequalities, Journal d'Analyse Mathématique, 2019, vol. 137, no 2, pp. 559-601. https://doi.org/10.1007/s11854-019-0004-z

9. Keselman V. M. The concept and criteria of the capacitive type of the non-compact Riemannian manifold based on the generalized capacity, Mathematical Physics and Computer Simulation, 2019, vol. 22, no. 2, pp. 21-32 (in Russian). https://doi.org/10.15688/mpcm.jvolsu.2019.2.2

10. Korol'kov S. A. Harmonic functions on Riemannian manifolds with ends, Abstract of Cand. Sci. (Phys.-Math.) Dissertation, Kazan, 2009, 18 p. (In Russian).

https://www.elibrary.ru/item.asp?id=15942555

11. Korolkov S. A., Losev A.G. Generalized harmonic functions of Riemannian manifolds with ends, Mathematische Zeitschrift, 2012, vol. 272, no. 1-2, pp. 459-472. https://doi.org/10.1007/s00209-011-0943-2

12. Li P., Tam L.-F. Harmonic functions and the structure of complete manifolds, Journal of Differential Geometry, 1992, vol. 35, no. 2, pp. 359-383. https://doi.org/10.4310/jdg/1214448079

13. Losev A. G., Filatov V. V. On capacitary characteristics of noncompact Riemannian manifolds, Russian Mathematics, 2021, vol. 65, no. 3, pp. 61-67. https://doi.org/10.3103/S1066369X21030063

14. Mazepa E. A. On the solvability of boundary value problems for quasilinear elliptic equations on noncompact Riemannian manifolds, Sibirskie Élektronnye Matematicheskie Izvestiya, 2016, vol. 13, pp. 1026-1034 (in Russian). https://doi.org/10.17377/semi.2016.13.081

15. Mazepa E. A. The Liouville property and boundary value problems for semilinear elliptic equations on noncompact Riemannian manifolds, Siberian Mathematical Journal, 2012, vol. 53, no. 1, pp. 134-145. https://doi.org/10.1134/S0037446612010119

16. Miklyukov V. M. Some criteria for parabolicity and hyperbolicity of the boundary sets of surfaces, Izvestiya: Mathematics, 1996, vol. 60, no. 4, pp. 763-809. https://doi.org/10.1070/IM1996v060n04ABEH000080

17. Murata M., Tsuchida T. Uniqueness of $L^{1}$ harmonic functions on rotationally symmetric Riemannian manifolds, Kodai Mathematical Journal, 2014, vol. 37, no. 1, pp. 1-15. https://doi.org/10.2996/kmj/1396008245

18. Sun Y. Uniqueness result for non-negative solutions of semi-linear inequalities on Riemannian manifolds, Journal of Mathematical Analysis and Applications, 2014, vol. 419, no. 1, pp. 643-661. https://doi.org/10.1016/j.jmaa.2014.05.011

19. Yau S.-T. Some function-theoretic properties of complete Riemannian manifold and their applications to geometry, Indiana University Mathematics Journal, 1976, vol. 25, no. 7, pp. 659-670. http://www.jstor.org/stable/24891285

Received 06.07.2021 
Alexander Georgievich Losev, Doctor of Physics and Mathematics, Professor, Department of Mathematical Analysis and Function Theory, Volgograd State University, pr. Universitetsky, 100, Volgograd, 400062, Russia.

ORCID: https://orcid.org/0000-0002-1072-8375

E-mail: alexander.losev@volsu.ru

Vladimir Vladimirovich Filatov, Assistant Lecturer, Department of Mathematical Analysis and Function Theory, Volgograd State University, pr. Universitetsky, 100, Volgograd, 400062, Russia.

ORCID: https://orcid.org/0000-0001-9559-6115

E-mail: filatov@volsu.ru

Citation: A.G. Losev, V.V. Filatov. Liouville type theorems for solutions of semilinear equations on non-compact Riemannian manifolds, Vestnik Udmurtskogo Universiteta. Matematika. Mekhanika. Komp'yuternye Nauki, 2021, vol. 31, issue 4, pp. 629-639. 


\section{А. Г. Лосев, В. В. Филатов \\ Теоремы типа Лиувилля для решений полулинейных уравнений на некомпактных римановых многообразиях}

Ключевые слова: теорема типа Лиувилля, полулинейные эллиптические уравнения, римановы многообразия, массивные множества, функция Лиувилля.

УДК 517.956.2

DOI: $10.35634 / \mathrm{vm} 210407$

В данной работе доказано, что функция Лиувилля, ассоциированная с полулинейным уравнением $\Delta u-g(x, u)=0$, тождественна нулю, тогда и только тогда когда существует только тривиальное ограниченное решение полулинейного уравнения на некомпактных римановых многообразиях. Этот результат обобщает соответствующий результат С. А. Королькова в случае стационарного уравнения Шрёдингера $\Delta u-q(x) u=0$. Так же введено понятие емкости компакта ассоцированого с стационарным уравнением Шрёдингера и доказано, что если емкость любого компакта равна нулю, то функция Лиувилля есть тождественный ноль.

Финансирование. Исследование выполнено при финансовой поддержке РФФИ в рамках научного проекта № 20-31-90110.

\section{СПИСОК ЛИТЕРАТУРЫ}

1. Каристи Г., Митидиери Э., Похожаев С. И. Теоремы Лиувилля для квазилинейных эллиптических неравенств // Доклады Академии наук. 2009. Т. 424. № 6. С. 741-747. https://elibrary.ru/item.asp?id=11695704

2. Cheng S.Y., Yau S.T. Differential equations on riemannian manifolds and their geometric applications // Communications on Pure and Applied Mathematics. 1975. Vol. 28. No. 3. P. 333-354. https://doi.org/10.1002/cpa.3160280303

3. Grigor'yan A. Analytic and geometric background of recurrence and non-explosion of the Brownian motion on Riemannian manifolds // Bulletin of the American Mathematical Society. 1999. Vol. 36. No. 2. P. 135-249. https://doi.org/10.1090/S0273-0979-99-00776-4

4. Grigor'yan A.A. On the existence of positive fundamental solutions of the Laplace equation on Riemannian manifolds // Mathematics of the USSR-Sbornik. 1987. Vol. 56. No. 2. P. 349-358. https://doi.org/10.1070/SM1987v056n02ABEH003040

5. Grigor'yan A., Hansen W. A Liouville property for Schrödinger operators // Mathematische Annalen. 1998. Vol. 312. No. 4. P. 659-716. https://doi.org/10.1007/s002080050241

6. Григорьян А.А., Лосев А.Г. О размерности пространств решений стационарного уравнения Шрёдингера на некомпактных римановых многообразиях // Математическая физика и компьютерное моделирование. 2017. Т. 20. № 3. С. 34-42. https://doi.org/10.15688/mpcm.jvolsu.2017.3.3

7. Grigor'yan A., Sun Y. On positive solutions of semi-linear elliptic inequalities on Riemannian manifolds // Calculus of Variations and Partial Differential Equations. 2019. Vol. 58. No. 6. 207. https://doi.org/10.1007/s00526-019-1645-6

8. Grigor'yan A., Verbitsky I. Pointwise estimates of solutions to semilinear elliptic equations and inequalities // Journal d'Analyse Mathématique. 2019. Vol. 131. No. 2. P. 559-601. https://doi.org/10.1007/s11854-019-0004-z

9. Кесельман В.М. Понятие и критерии емкостного типа некомпактного риманова многообразия на основе обобщенной емкости // Математическая физика и компьютерное моделирование. 2019. T. 22. № 2. C. 21-32. https://doi.org/10.15688/mpcm.jvolsu.2019.2.2

10. Корольков С. А. Гармонические функции на римановых многообразиях с концами: автореф. дис. ... к-та физ.-матем. наук. Казань, 2009. 18 c. https://www.elibrary.ru/item.asp?id=15942555

11. Korolkov S. A., Losev A. G. Generalized harmonic functions of Riemannian manifolds with ends // Mathematische Zeitschrift. 2012. Vol. 272. No. 1-2. P. 459-472.

https://doi.org/10.1007/s00209-011-0943-2 
12. Li P., Tam L.-F. Harmonic functions and the structure of complete manifolds // Journal of Differential Geometry. 1992. Vol. 35. No. 2. P. 359-383. https://doi.org/10.4310/jdg/1214448079

13. Лосев А. Г., Филатов В.В. О некоторых емкостных характеристиках некомпактных римановых многообразий // Изв. вузов. Матем. 2021. № 3. С. 67-75. https://doi.org/10.26907/0021-3446-2021-3-67-75

14. Мазепа Е.А. О разрешимости краевых задач для квазилинейных эллиптических уравнений на некомпактных римановых многообразиях // Сибирские электронные математические известия. 2016. T. 13. C. $1026-1034$. https://doi.org/10.17377/semi.2016.13.081

15. Мазепа Е. А. Лиувиллево свойство и краевые задачи для полулинейных эллиптических уравнений на некомпактных римановых многообразиях // Сибирский математический журнал. 2012. T. 53. № 1. C. 165-179. http://mi.mathnet.ru/smj2296

16. Миклюков В. М. Некоторые признаки параболичности и гиперболичности граничных множеств поверхностей // Изв. РАН. Сер. матем. 1996. Т. 60. № 4. С. 111-158. https://doi.org/10.4213/im80

17. Murata M., Tsuchida T. Uniqueness of $L^{1}$ harmonic functions on rotationally symmetric Riemannian manifolds // Kodai Mathematical Journal. 2014. Vol. 37. No. 1. P. 1-15. https://doi.org/10.2996/kmj/1396008245

18. Sun Y. Uniqueness result for non-negative solutions of semi-linear inequalities on Riemannian manifolds // Journal of Mathematical Analysis and Applications. 2014. Vol. 419. No. 1. P. 643-661. https://doi.org/10.1016/j.jmaa.2014.05.011

19. Yau S.-T. Some function-theoretic properties of complete Riemannian manifold and their applications to geometry // Indiana University Mathematics Journal. 1976. Vol. 25. No. 7. P. 659-670. http://www.jstor.org/stable/24891285

Поступила в редакцию 06.07 .2021

Лосев Александр Георгиевич, д.ф.-М.н., профессор, кафедра математического анализа и теории функций, Волгоградский государственный университет, 400062, Россия, г. Волгоград, пр. Университетский, 100.

ORCID: https://orcid.org/0000-0002-1072-8375

E-mail: alexander.losev@volsu.ru

Филатов Владимир Владимирович, ассистент, кафедра математического анализа и теории функций, Волгоградский государственный университет, 400062, Россия, г. Волгоград, пр. Университетский, 100.

ORCID: https://orcid.org/0000-0001-9559-6115

E-mail: filatov@volsu.ru

Цитирование: А. Г. Лосев, В. В. Филатов. Теоремы типа Лиувилля для решений полулинейных уравнений на некомпактных римановых многообразиях // Вестник Удмуртского университета. Математика. Механика. Компьютерные науки. 2021. Т. 31. Вып. 4. С. 629-639. 